\title{
Knowledge of Nutritional Issues among Osteopaths in Austria: A Cross-Sectional Study
}

Jürgen Putschögl MSc ${ }^{1}$, Dr. Gebhard Woisetschläger ${ }^{2}$

\section{ABSTRACT}

Introduction: Osteopaths are important actors in the Austrian healthcare system. High prevalence rates for diseases associated with nutrition, as well as studies from other countries, imply that osteopaths are confronted with questions regarding nutrition in the course of their work.

Aim: The purpose of this study was to survey osteopath's knowledge of nutritional issues in a crosssectional study and analyse factors that influence nutrition knowledge. Furthermore, it will be investigated if osteopaths are confronted with problems or questions regarding nutrition.

Material and Methods: With the help of schools of osteopathy, all osteopaths, who could be found in Austria, were asked to participate in an online survey. As instruments of research, the General Nutrition Knowledge Questionnaire (GNKQ) and a second questionnaire were used.

Results: The average rate of correctly answered questions was $74.4 \%$ for the GNKQ and $37.2 \%$ for the Temple Questionnaire $(n=188)$.

Discussion: Compared to other occupational groups in the American or British healthcare system, Austrian osteopaths' average nutritional knowledge is slightly higher. Only nutrition experts and people employed at centres specializing in eating disorders obtained results that are more favourable. Further surveys ought to develop valid instruments for Austria and attempt to define which amount of nutrition knowledge can be considered as adequate for certain occupational groups.

Keywords: nutrition knowledge, knowledge of nutritional issues, osteopathy, General Nutrition Knowledge Questionnaire

DOI: https://doi.org/10.35740/EJOR.2020.2.1.3 


\section{BACKGROUND}

Osteopaths are important actors in the Austrian healthcare system. High prevalence rates for diseases associated with nutrition imply that osteopaths are confronted with nutrition issues in their daily work (1). They do not offer nutrition counselling per se in Austria (2), but they function as advisors concerning numerous patients' health issues. Thus they can contribute a substantial share in developing patients ' (3) competence in health issues and act as pioneers in the course of interdisciplinary cooperation (4). The nutrition knowledge of Austrian osteopaths has not yet been surveyed, but it serves as a basis for answering and categorizing questions concerning nutrition.

There is no standardized or scientific definition of the term nutrition knowledge in the Germanspeaking world, but the term is used nevertheless. Nutrition knowledge is mainly seen as knowledge concerning proper nutrition according to nationally valid suggestions of expert associations or as healthy or unhealthy food and nutrition (5).

Parmenter et al. (6) define nutrition knowledge more broadly as a term which is essentially determined by four aspects:

- Do people know current suggestions concerning nutrition made by expert associations or nutritionists?

- Can people name a food that contains the suggested nutrients if the suggestions were not made in connection with the respective foods?

- Are people able to choose the healthiest option among several foods offered?

- Do people know which potential health effects the consumption or the lack of certain foods have?

Surveys from other countries imply that the general nutrition knowledge of people employed in healthcare is fragmentary $(3,7)$. Moreover, it is shown that nutrition issues do play a role in osteopathic work $(3,8-10)$.

So far, no scientific paper has been published on the topic of Nutrition Knowledge among Austrian osteopaths. The aim of this study was to survey osteopath's knowledge of nutritional issues in a cross-sectional survey and investigate if ques- tions regarding nutrition are relevant for osteopaths in their daily work. Apart from that, potential factors which influence general nutrition knowledge will be analyzed.

\section{MATERIAL AND METHODS}

In order to evaluate nutrition knowledge, two questionnaires were combined: On the one hand, the General Nutrition Knowledge Questionnaire (GNKQ), which was developed by Parmenter and Wardle (6), and on the other hand, a questionnaire by Temple et al. (11) Additionally, sociodemographic questions were introduced.

The GNKQ was developed to investigate the general nutrition knowledge of adults (12). The questionnaire, which was revised in 2016, is validated and freely available (13). It was initially designed for Great Britain and had to be adapted for German-speaking countries. For this purpose, the questionnaire was translated, and cultural differences concerning certain foods were considered.

The General Nutrition Knowledge Questionnaire consists of four independent sections, each of which investigates a different aspect of nutrition knowledge. Subscales are knowledge of expert advice (nine questions), knowledge of food groups (ten questions), knowledge of food choice (13 questions), knowledge of diseases associated with nutrition (16 questions). As a further instrument to investigate nutrition knowledge, the questionnaire by Temple et al. was used. This questionnaire consists of 16 questions with four multiple-choice answers each, only one of which is correct. Initially, this questionnaire was designed to survey Canadian doctors' nutrition knowledge, and the questions can be regarded as more specific or more medical compared to the GNKQ.

This study's target group were all practising Austrian osteopaths who graduated from an educational institution approved by the Austrian Osteopathic Society. In the quantitative cross-sectional study, a complete investigation of all osteopaths practising in Austria was aimed.

The Viennese School of Osteopathy, the International Academy of Osteopathy and the Austrian 
Osteopathic Society were asked to forward the questionnaire to their graduates and members per email. The International Academy of Osteopathy denied cooperation. In order to reach people who had not graduated from the Viennese School of Osteopathy or were no members of the Austrian Osteopathic Society, national organizations, graduates' lists of German and Swiss schools of osteopathy, lists used in former studies, and the telephone directory were used. It is impossible to gather the total number of osteopaths practising in Austria, as osteopathy is neither an approved occupational field nor is there an obligation for osteopaths to register with a professional association or a government agency. Due to multiple entries and the Viennese School of Osteopathy and the Austrian Osteopathic Society's data protection guidelines, the total number of osteopaths contacted cannot be given.

The questionnaire was emailed using an online tool (Survey Monkey) on June 30th, 2017. On July 13th, 2017, a reminder was sent to the osteopaths, and on July 19th, 2017, the collection of data was concluded. 188 of the 280 received online questionnaires could be included in the analysis. Ninety-two questionnaires were labelled as incomplete and were therefore excluded from the survey. Questionnaires, where one or more questions had not been answered were labelled as incomplete.

\section{Statistics}

The data was exported from the survey platform Survey Monkey as a Microsoft Excel table. The Temple-questionnaire score, the GNKQ total score and the scores for the four subscales were calculated from the results of the questionnaires. Subsequently, the percentage of correct answers was calculated.

Descriptive data of the scores include mean, standard deviation, 95\% confidence interval and standard error of the mean, as well as minima, maxima and quartile. The survey of differences among subgroups of osteopaths concerning nutrition knowledge was carried out through an analysis of variance with a single-factor, univariate Principle Component Analysis of total scores and individual scores of the subscales $(\alpha=0.05)$.
In the course of this, the following was investigated due to the choice of appropriate factors: differences between men and women, differences concerning the basic profession, differences between schools of osteopathy, differences between osteopaths with or without further education focusing on nutrition, differences between osteopaths for whom nutrition is relevant in their work and those for whom this is not the case. If several significant influences of factors concerned the same dependent variable, all relevant factors and their interactions were then considered in a further analysis of variance (linear model with type III sum of squares). As there were no significant interactions, these analyses were repeated without interaction terms.

\section{RESULTS}

Altogether 188 questionnaires were analysed. The collective is described in table 1.

36 of the 188 participants surveyed completed further training in the field of nutrition.

Table 1 - Participants

\begin{tabular}{|c|c|c|}
\hline Gender & $\mathbf{N}$ & $\%$ \\
\hline Male & 38 & 20.21 \\
\hline Female & 150 & 79.79 \\
\hline \multicolumn{3}{|l|}{ Age } \\
\hline Younger than 35 years & 34 & 18.09 \\
\hline Between 35 and 45 years & 69 & 36.7 \\
\hline Between 45 and 55 years & 60 & 31.91 \\
\hline Between 55 and 65 years & 22 & 11.7 \\
\hline Older than 65 years & 3 & 1.6 \\
\hline \multicolumn{3}{|l|}{ Basic profession } \\
\hline Physiotherapist & 158 & 84.04 \\
\hline Doctor & 16 & 8.51 \\
\hline Other basic professions & 14 & 7.45 \\
\hline \multicolumn{3}{|l|}{ School of Osteopathy } \\
\hline Vienna School of Osteopathy & 139 & 74.33 \\
\hline International School of Osteopathy & 25 & 13.37 \\
\hline Other schools of osteopathy & 23 & 12.3 \\
\hline Years since Graduation & $n$ & $\%$ \\
\hline $0-5$ years & 56 & 29.79 \\
\hline $5-10$ years & 59 & 31.38 \\
\hline $10-15$ years & 42 & 22.34 \\
\hline $15-20$ years & 26 & 13.83 \\
\hline More than 20 years & 5 & 2.66 \\
\hline
\end{tabular}


Tauch A. - European Journal of Osteopathic Research www.ejor.org · elSSN 2699-2027

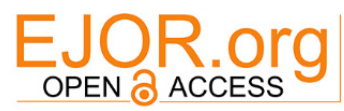

European Journal of Osteopathic Research

Table 2: Percentage of correct answers for the complete questionnaire and GNKQ respectively

\begin{tabular}{|c|c|c|c|}
\hline $\begin{array}{c}\text { Percentage of correct } \\
\text { answers for }\end{array}$ & $\begin{array}{l}\text { Complete questionnaire } \\
\text { (104 questions) }\end{array}$ & $\begin{array}{c}\text { GNKQ } \\
\text { (88 questions) }\end{array}$ & $\begin{array}{c}\text { Temple } \\
\text { (16 questions) }\end{array}$ \\
\hline valid (n) & 188 & 188 & 188 \\
\hline missing (n) & 0 & 0 & 0 \\
\hline $\min$ & 46.1 & 52.2 & 6.2 \\
\hline P25 & 64.4 & 70.4 & 25.0 \\
\hline median & 69.2 & 75.0 & 37.5 \\
\hline P75 & 73.0 & 78.7 & 50.0 \\
\hline $\max$ & 85.5 & 93.1 & 75.0 \\
\hline mean & 68.9 & 74.7 & 37.1 \\
\hline standard deviation & 7.2 & 6.9 & 14.9 \\
\hline 95\% Cl lower & 67.9 & 73.7 & 35.0 \\
\hline 95\% Cl upper & 70.0 & 75.7 & 39.2 \\
\hline standard error & 0.5 & 0.5 & 1.1 \\
\hline
\end{tabular}

The share of correct answers was at $74.7 \pm 6.9 \%$ for the GNKQ and at $37.1 \pm 14.9 \%$ for the Temple-Questionnaire (table 2).

The factor "Education in the Field of Nutrition" generated significant differences, especially regarding the results of the whole questionnaire, the Temple-Questionnaire, the GNKQ and single subscales (table 3 ).

The analysis of variance (linear model with type III sum of squares) without interaction term revealed the factor "School of Osteopathy" as the unique significant factor for the subscale "Choice of Foods" $(\mathrm{F}(2,183)=4.6179, \mathrm{p}=0.011)$. The

Table 3: Statistically significant results $(p<0.05)$ of the single-factor, univariate Principle Component Analysis of total scores and individual scores

\begin{tabular}{|c|c|c|}
\hline Dependent Variable & Factor & $\mathbf{F}, \mathbf{p}$ \\
\hline Subscale Expert Advice & - & - \\
\hline Subscale Food Groups & $\begin{array}{c}\text { Additional Education in the Field } \\
\text { of Nutrition }\end{array}$ & $F(1,186)=11.673, p=0.0008$ \\
\hline \multirow[t]{2}{*}{ Subscale Choice of Foods } & $\begin{array}{c}\text { Additional Education in the Field } \\
\text { of Nutrition }\end{array}$ & $F(1,186)=3.9594, p=0.048$ \\
\hline & School of Osteopathy & $F(2,184)=4.9912, p=0.0077$ \\
\hline $\begin{array}{c}\text { Subscale Diseases } \\
\text { Associated with Nutrition }\end{array}$ & - & - \\
\hline GNKQ Total & $\begin{array}{c}\text { Additional Education in the Field } \\
\text { of Nutrition }\end{array}$ & $F(1,186)=7.149, p=0.0082$ \\
\hline Temple Questionnaire & $\begin{array}{c}\text { Additional Education in the Field } \\
\text { of Nutrition }\end{array}$ & $F(1,186)=24.868, p<0.0001$ \\
\hline \multirow[t]{2}{*}{ Total Score } & $\begin{array}{c}\text { Additional Education in the Field } \\
\text { of Nutrition }\end{array}$ & $F(1,186)=14.045, p=0.0002$ \\
\hline & School of Osteopathy & $F(2,184)=3.6241, p=0.029$ \\
\hline
\end{tabular}


factor "Education in the Field of Nutrition" wanot analyzed as significant after subtraction of explainable variance of school of osteopathy $(\mathrm{F}(1,183)=3.0016, \mathrm{p}=0.085)$.

Concerning the dependent variable "Total Score" there is only a significant result for the factor "Additional Education in the Field of Nutrition" $(\mathrm{F}(1.183)=12.171, \mathrm{p}=0.00061)$. There is no significant influence for the factor "School of Osteopathy" $(\mathrm{F}(2.183)=2.8838, \mathrm{p}=0.058)$.

\section{Relevance of questions associated with nutrition in everyday professional life}

Altogether $84.4 \%(n=157)$ of the osteopaths surveyed stated that nutrition is relevant in their everyday professional life. More than a third (38.8\%) report being asked questions about nutrition frequently, $45.7 \%$ sometimes, and $14.9 \%$ rarely. $0.5 \%$ are never confronted with questions concerning nutrition.

Almost all osteopaths surveyed (99.5\%) generally include nutritional issues in their diagnoses. More than half of them $(51.6 \%)$ do so frequently, $37.8 \%$ sometimes, and $10.1 \%$ rarely. Only $0.5 \%$ never include nutritional issues in their diagnoses.

\section{DISCUSSION}

Classification of results is difficult. The question whether or not the scores of the GNKQ (74.4\%) can be seen as sufficient cannot be satisfactorily answered. Often highly different instruments are applied for the investigation of nutrition knowledge. Some of them were, like in this study, not validated (12). Other scientific papers, which contained mainly an older version of the GNKQ quoted the following percentages of correctly answered questions for people employed at a centre for eating disorders: $87.9 \%$ (nutrition experts), $78.5 \%$ (doctors), $72.5 \%$ (other health professions) and $73.2 \%$ (patients) (14). Disability care workers only reached an average of $56.6 \%$ of correctly answered questions (15), female athletes $57.6 \%$ (16), male athletes 48\% (17), the "general public" $63.1 \%$, nutrition experts in other settings $86.2 \%$ (16), and military personnel $52.7 \%$ (18).
When a different instrument was used, students of osteopathy in America answered 69.5\% of questions correctly (12). Independent of comparisons of single occupational groups Hargrove et al. determined a minimum of sufficient nutrition knowledge of osteopaths with $72.5 \%$ of correctly answered questions; Parker et al. imposed even stricter standards with $80 \%$.

For the Temple questionnaire, different results were found. The osteopaths were able to answer $37.5 \%$ of the questions correctly. Surveys of doctors in other countries showed a share of correctly answered questions of $63.9 \%-52.1 \%$ (5, 19-21). The reason for this is undoubtedly the field of work and education. The Temple questionnaire consists of more specific questions than the GNKQ. These focus strongly on diseases associated with nutrition.

Further education in the area of nutrition was analyzed as the determining factor of general nutrition knowledge. The factor "Additional Education in the Field of Nutrition" influenced the score reached in both questionnaires and the total result. This corresponds with surveys that showed that a higher educational qualification in general and especially additional education in nutrition can constitute a higher nutrition knowledge $(22,23)$. Contrary to the results of other studies, no gender-related differences could be analysed in this study. In general, women are attested a higher nutrition knowledge (22). This was partly confirmed in other studies which investigated nutrition knowledge in healthcare professions $(2,20,23)$, or men reached higher scores for nutrition knowledge $(17,19)$ or no differences were analysed (24).

Independent of osteopaths' primary responsibilities, they are confronted with questions concerning nutrition in their professional life and give advice on nutrition $(2,3,11,12)$. This could be partly confirmed in this study. Moreover, nutrition issues are frequently included in the diagnosis.

Conclusion

The general nutrition knowledge (GNKQ) of osteopaths was above the mean of other healthcare professions with $74.7 \%$. Only nutritionists scored significantly higher in all surveys. But more specific questions were answered considerably worse 
Tauch A. - European Journal of Osteopathic Research www.ejor.org · elSSN 2699-2027

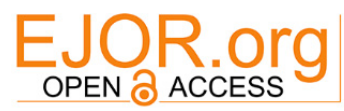

European Journal of Osteopathic Research

than by doctors. Osteopaths with additional education in the area of nutrition showed a higher general and detailed nutrition knowledge than those without further education in this field.

Summarising, it can be stated that both comparisons and assessment of general nutrition knowledge are generally difficult, as cultural and systemic factors can cause differences. In the case of this study, this is aggravated by the fact that a questionnaire was used, which was not validated for this collective. This limits the validity of results on the one hand, and on the other hand, it shows the necessity of developing an adequate instrument. So far, there is no standardized, validated German tool to investigate general nutrition knowledge. The application of a standardized and validated instrument of investigation should be promoted in this area of research. To what extent nutrition knowledge of osteopaths in Austria can be regarded as sufficient despite all existing limitations remains to be seen. Because neither the instrument used nor other tools state limiting values for sufficient nutrition knowledge in healthcare professions. Moreover, it cannot be ruled out that generally, people who took part in the study who per se show a higher interest in questions concerning nutrition.

Independent of the significance of this study it seems that nutrition questions are present in osteopathic work. Therefore nutrition knowledge should be paid attention to, not just to guarantee interdisciplinary cooperation and optimum care of patients. This is the first study which investigates nutrition knowledge of osteopaths in Austria in a cross-sectional study. Further effort should be taken to promote the development of a suitable instrument for the investigation of nutrition knowledge in general and in healthcare professions, including osteopaths

\section{Discloser}

The author has no personal, financial or institutional interest in any of the drugs, materials or devices described in this article.

\section{Author details}

${ }^{1}$ Jürgen Putschögl, Hellmonsödt, Austria

${ }^{2}$ Dr. Gebhard Woisetschläger, Austria

\section{Correspondence}

Jürgen Putschögl

Teichfeld 4

4202 Hellmonsödt

Austria

Email: juergen.putschoegl@me.com

Received: October 29th 2020 Accepted: December 16th 2020 Published: December 18th 2020

\section{REFERENCES}

1. Statistik Austria im Auftrag des Bundesministeriums für Gesundheit, editor. Österreichische Gesundheitsbefragung 2014. Hauptergebnisse des Austrian Health Interview Survey (ATHIS) und methodische Dokumentation. Wien: Statistik Austria im Auftrag des Bundesministeriums für Gesundheit; 2014.

2. VEÖ. Leitfaden Prüfkriterien für individuelle Befähigung Ernährungsberatung. 2017.

3. Parker, W., Steyn, N. P., Levitt, N. S., \& Lombard, C. J. (2010). They think they know but do they? Misalignment of perceptions of lifestyle modification knowledge among health professionals. Public Health Nutrition, 14(8), 1429-1438. https://doi.org/10.1017/s1368980009993272

4. DiMaria-Ghalili, R. A., Mirtallo, J. M., Tobin, B. W., Hark, L., Van Horn, L., \& Palmer, C. A. (2014). Challenges and opportunities for nutrition education and training in the health care professions: intraprofessional and interprofessional call to action. The American Journal of Clinical Nutrition, 99(5), 1184S1193S. https://doi.org/10.3945/ajcn.113.073536

6. Parmenter, K., \& Wardle, J. (1999). Development of a general nutrition knowledge questionnaire for adults. European Journal of Clinical Nutrition, 53(4), 298-308. https://doi.org/10.1038/sj.ejcn.1600726

7. Mowe, M., Bosaeus, I., Rasmussen, H. H., Kondrup, J., Unosson, M., Rothenberg, E., ... The Scandinavian Nutrition group. (2008). Insufficient nutritional knowledge among health care workers? Clinical Nutrition, 27(2), 196-202. https://doi.org/10.1016/j.clnu.2007.10.014 
Tauch A. - European Journal of Osteopathic Research www.ejor.org · elSSN 2699-2027

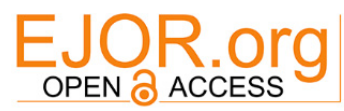

European Journal of Osteopathic Research

8. Meuser-Scheliga M. Welchen Stellenwert hat die Ernährung in der osteopathischen Praxis. Esthal: Donau-Universität Krems; 2009.

9. Munelly O. A survey to investigate whether Osteopath's give Nutritional Advice to their Patients'. London: British School of Osteopathy; 2004.

10. Hargrove, E. J., Berryman, D. E., Yoder, J. M., \& Beverly, E. A. (2017). Assessment of Nutrition Knowledge and Attitudes in Preclinical Osteopathic Medical Students. Journal of Osteopathic Medicine, 117(10), 622-633. https://doi.org/10.7556/jaoa.2017.119

11. Temple NJ. Survey of nutrition knowledge of Canadian physicians. J Am Coll Nutr. 1999;18(1):26-9.

12. Parmenter, K., \& Wardle, J. (1999). Development of a general nutrition knowledge questionnaire for adults. European Journal of Clinical Nutrition, 53(4), 298-308. https://doi.org/10.1038/sj.ejcn.1600726

13. Kliemann, N., Wardle, J., Johnson, F., \& Croker, H. (2016). Reliability and validity of a revised version of the General Nutrition Knowledge Questionnaire. European Journal of Clinical Nutrition, 70(10), 11741180. https://doi.org/10.1038/ejcn.2016.87

14. Ho A. S. L., SOH, N. L., WALTER, G., \& TOUYZ, S. (2011). Comparison of nutrition knowledge among health professionals, patients with eating disorders and the general population. Nutrition \& Dietetics, 68(4), 267-272. https://doi.org/10.1111/j.17470080.2011.01549.x

15. Hamzaid, N. H., Flood, V. M., Prvan, T., \& O’Connor, H. T. (2018). General nutrition knowledge among carers at group homes for people with intellectual disability. Journal of Intellectual Disability Research, 62(5), 422-430. https://doi.org/10.1111/jir.12480

16. Spendlove, J. K., Heaney, S. E., Gifford, J. A., Prvan, T., Denyer, G. S., \& O'Connor, H. T. (2011). Evaluation of general nutrition knowledge in elite Australian athletes. British Journal of Nutrition, 107(12), 1871-1880. https://doi.org/10.1017/s0007114511005125

17. De Souza Silveira, R., Kratzenstein, S., Hain, G., Mayer, F., \& Carlsohn, A. (2015). Nutrition Knowledge Quiestionnaire - Modified and Validated for the Use in German Adolescent Athletes. Deutsche Zeitschrift Für Sportmedizin, 2015(09), 248252. https://doi.org/10.5960/dzsm.2015.190

18. Kulslen, C. J., Farrugia, J.-L., Prvan, T., \& O'Connor, H. T. (2016). Relationship between general nutrition knowledge and diet quality in Australian military personnel. British Journal of Nutrition, 115(8), 14891497. https://doi.org/10.1017/s0007114516000532

19. Daradkeh G, Al Bader K, Singh R. The Nutrition Knowledge of Primary Care Physicians in the State of Qatar2012.
20. Allafi, A. R., Alajmi, F., \& Al-Haifi, A. (2012). Survey of nutrition knowledge of physicians in Kuwait. Public Health Nutrition, 16(7), 1332-1336. https://doi.org/10.1017/s1368980012003606

21. Al-Zahrani AM, Al-Raddadi RM. Nutritional knowledge of primary health care physicians in Jeddah, Saudi Arabia. Saudi medical journal. 2009;30(2):284-7. Epub 2009/02/10. PubMed PMID: 19198721.

22. Parmenter, K., Waller, J., \& Wardle, J. (2000). Demographic variation in nutrition knowledge in England. Health Education Research, 15(2), 163-174. https://doi.org/10.1093/her/15.2.163

23. Dumic, A., Miskulin, M., Pavlovic, N., Orkic, Z., BilicKirin, V., \& Miskulin, I. (2018). The Nutrition Knowledge of Croatian General Practitioners. Journal of Clinical Medicine, 7(7), 178. https://doi.org/10.3390/jcm7070178

24. Kullen, C. J., Iredale, L., Prvan, T., \& O'Connor, H. T. (2016). Evaluation of General Nutrition Knowledge in Australian Military Personnel. Journal of the Academy of Nutrition and Dietetics, 116(2), 251-258. https://doi.org/10.1016/j.jand.2015.08.014 